\title{
Freeze-thaw performance of granular roads stabilized with optimized gradation and clay slurry
}

\author{
Ziqiang Xue \\ Graduate Research Assistant, Department of Civil, Construction and Environmental Engineering, Iowa \\ State University, Ames, IA, USA \\ Jeramy C. Ashlock \\ Richard L. Handy Associate Professor, lepartment of Civil, Construction and Environmental Engineering, \\ Iowa State University, Ames, IA, USA
}

\section{Bora Cetin}

Associate Professor, Department of Civil and Environmental Engineering, Michigan State University, East Lansing, MI, USA

\section{Sajjad Satvati}

Graduate Research Assistant, Department of Civil, Construction and Environmental Engineering, Iowa State University, Ames, IA, USA

\section{Halil Ceylan}

Professor, Department of Civil, Construction and Environmental Engineering, Iowa State University, Ames, IA, USA

\section{Yijun $\mathrm{Wu}$}

Graduate Research Assistant, Department of Civil, Construction and Environmental Engineering, Iowa State University, Ames, IA, USA

\section{Cheng Li}

Assistant Professor, School of Highway, Changan University, Xi'an, Shanxi Province, China

\begin{abstract}
A recently-developed granular road stabilization method was applied to four test sections in different Iowa counties. This new method uses an optimized target gradation achieved by blending existing surface materials with two to three fresh aggregate types to achieve the tightest possible particle packing. A clay slurry is also incorporated into the top two inches during mixing of the surface aggregates to increase the plasticity and binding characteristics to reduce material loss. The performance of the test sections was measured using field dynamic cone penetrometer (DCP) tests, falling weight deflectometer (FWD) tests, and nuclear density gauge tests. The test results are compared to those of adjacent control sections as well as test sections stabilized using Portland cement and steel slag. Among the stabilization methods applied in the test sections, the Optimized Gradation with Clay Slurry stabilization method and the cement-treated 4" surface course was the most costeffective.
\end{abstract}

Keywords: Stabilization, granular roadway, elastic modulus, falling weight deflectometer, shear strength, dynamic cone penetrometer 


\section{INTRODUCTION}

Granular-surfaced roads commonly provide access between rural and urban areas for hauling agricultural products to market, but high traffic loads and large numbers of freeze-thaw cycles in seasonally cold regions can damage the road surface, especially during springtime. Water present in the near-surface layers experiences phase changes due to the freezing and thawing [1]-[3], resulting in aggregate deterioration and various distresses such as loss of crown, washboarding, potholes, rutting, and raveling. Moreover, the mechanical properties of the surface layers, including gradation, shear strength, and stiffness, are altered due to the material property changes. Regular maintenance is therefore required to maintain road serviceability, which can be costly for DOTs or secondary roads agencies.

Stiffness and strength, the main factors in road design, depend on the quality, shape, aggregate size, thickness, and density of the surface layer [4]-[6]. Environmental conditions and traffic loads alter the surface elastic modulus and shear strength, and knowledge of such mechanistic factors can help in evaluating road performance. Previous studies have shown the significant effects of freeze-thaw cycles on degrading the mechanical properties of granular layers [7]-[11]. Stabilization of granular roadways with quarry fines byproducts has been proven to improve these properties by increasing plasticity and providing tighter bonding between aggregates [12]-[14]. Quarry fines are typically found in one of three distinct formats: screenings, pond fines, and baghouse fines, all of which are waste products of rock-crushing processes [15].

This study investigates the effects of utilizing a clay slurry quarry fines byproduct to provide improved binding between surface aggregates in four granular-surface road test sections. FWD and DCP tests were conducted on test sections and control sections to monitor the elastic modulus and shear strength of the surface aggregate layers subjected to seasonal freezing and thawing cycles. Nuclear gauge density tests were also conducted to compare the density and moisture content of the granular surface layers. The performance of sections stabilized with the clay slurry and an optimized gradation was compared with that of adjacent test sections stabilized with Portland cement and steel slag, as well as control sections.

\section{MATERIALS}

To cover a wide range of the state's climate conditions, subgrade types, and aggregate sources, the test sections were constructed in Cherokee, Hamilton, Howard, and Washington counties distributed across Iowa (Figure 1). The test sections were constructed by stabilizing the top 4" of the granular surface layers. For the Optimized Gradation with Clay Slurry (OGCS) sections constructed in all four counties, the top 4" of surface course materials were blended in optimized proportions, after which clay slurry was sprayed and mixed into the top 2". The 4"thick steel slag sections were constructed in Howard and Cherokee counties using conventional granular roadway construction methods, and a 4" thick cement-treated surface course was constructed in Washington County using the county's wheel-loader mounted milling machine.

For the OGCS test sections, an optimized gradation using existing surface materials and locally available fresh aggregates was first determined using the spreadsheet tool published along with the TR-685 project report [25]. A predetermined depth of existing aggregates was first ripped using a motor grader, after which fresh aggregates were spread and blade-mixed in several passes to achieve a uniform gradation. To improve upon a previous study that used powdered bentonite for plasticity, a newly available clay-slurry quarry product was applied to the optimized gradation mixture during construction of the OGCS test sections in all four counties. The clay slurry was sprayed onto the aggregate mixtures using a self-unloading tanker truck, then blade-mixed into the top 2" of aggregates using numerous motor grader passes until the material had 
somewhat dried out. The surface was then shaped, and a few compaction passes were applied using rubber-tire rollers to accommodate the wet mixture that tended to stick to smooth-drum vibratory rollers. To achieve an immediately drivable surface, a light covering of fresh surface aggregates (approximately two 13-ton truckloads for each 500$\mathrm{ft}$ long test section) were spread over the top and pressed in with the rubber-tired roller. While the resulting surfaces were very wet immediately following construction, they were passable by traffic and typically dried up within 24-48 hours.

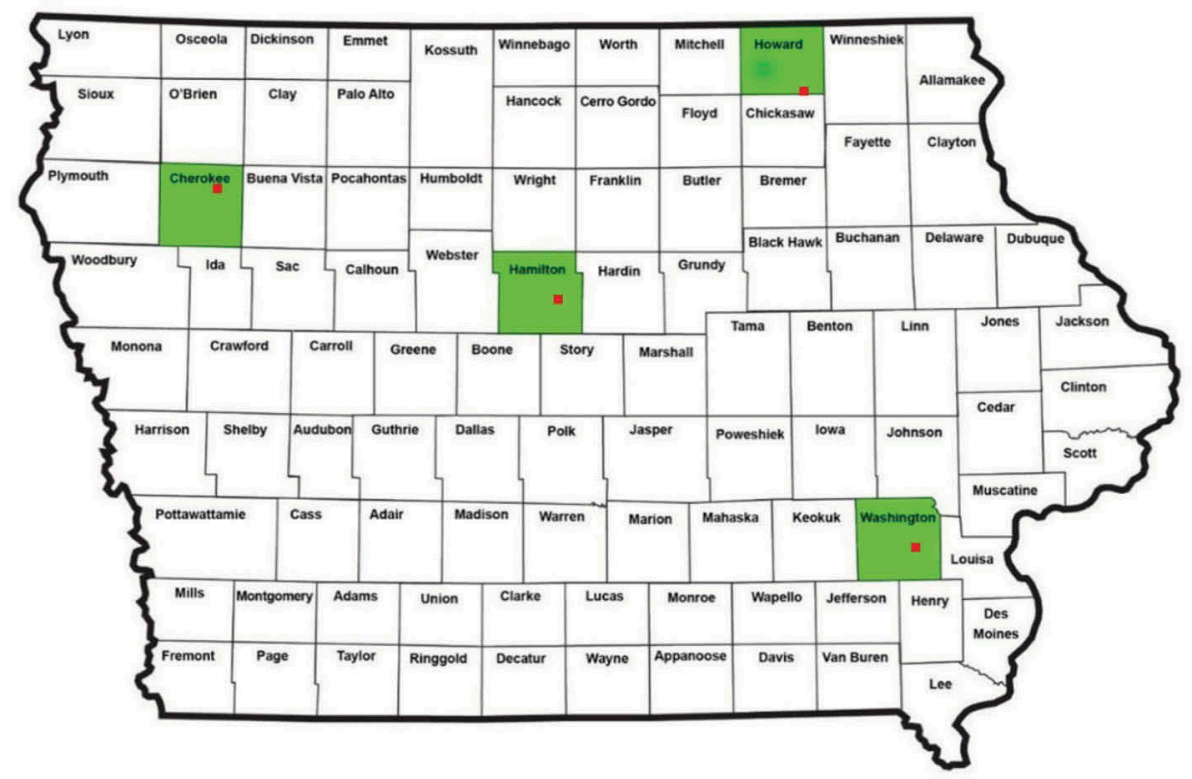

Figure 1. Locations of the test sections in four Iowa counties (Red dots show locations of the actual test sections).

\subsection{Steel slag surface}

Steel slag (SS) is an industrial byproduct commonly used as a stabilizer or amendment in roadway systems. Under compaction and road traffic, SS usually evolves into a high strength material with the capability for self-stabilization. In this study, the SS material was collected from Phoenix Services, LLC, in Wilton, IA. The full depth of the existing surface aggregate was first ripped down to the subgrade and hauled away and the slag then dumped in thin lifts sprayed with water and bladed. After shaping the surface, at least four passes of a rubber-tire roller were made, followed by a few passes of a vibratory smooth-drum roller.

\subsection{Cement treated aggregate surface course}

In this study, 7\% Portland cement by dry weight was blended into a 4-in. (101.6-mm) thick surface aggregate course in Washington County without treating the subgrade. The cement was first spread over the test section, then mixed full-depth using a 60-in. wide RoadHog milling machine which was mounted on a Caterpillar 938M Wheel Loader and attached to a water feeder truck by a hose system. After mixing, additional water was sprayed with 
a water truck and the surface was shaped with a grader. The surface was compacted with four passes of a rubber tire roller immediately followed by a smooth-drum vibratory roller to reduce the compaction delay time.

\subsection{Laboratory testing of construction materials}

After construction, laboratory tests were performed on samples from both the control sections and the stabilized sections. Sieve and hydrometer analyses were performed according to ASTM Methods D6913 and D7928 respectively, along with Atterberg limits tests (ASTM D4318) with classification by the AASHTO and USCS systems (ASTM D3282 \& D2487). The index properties and USCS classifications of the materials sampled from the field sections summarized in Table 1 show that, despite the addition of claysized particles, the OGCS sections all had lower fines contents than their nearby control sections that contained aggregates abraded and broken down by traffic loading. The control section materials in Cherokee county were non-plastic, i.e., sandy river gravel was the primary source of surfacing material there, while in the other counties crushed limestone having fines with some plasticity was typically used. The slag sections also had very little fines contents from the slag source discussed in this paper. All sections were constructed on a relatively stiff subgrade layer.

\section{TESTING METHODOLOGY AND RESULTS}

To determine freezing and thawing effects, field tests were performed at five points on each se ction during winter 2018 and spring 2019. FWD and DCP tests were conducted to evaluate the elastic modulus and shear strength, respectively, of the granular surface and subgrade layers, and nuclear-density gauge tests were performed to determine moisture content and density of each test section. The test methods and results are described in the following sections.

\subsection{Dynamic Cone Penetration (DCP) tests}

DCP tests were conducted to track relative changes in shear-strength profiles in terms of correlated California bearing-ratio (CBR) values. The road system profile was treated as a two-layered system consisting of an aggregate surface layer over a subgrade layer. The thicknesses of the surface layers were estimated based on the DCP data by determining the point at which the plot of cumulative depth versus the number of cumulative blows exhibited a sudden change in slope [1]. The correlated CBR values (denoted DCP-CBR) were then averaged over the depth of the aggregate surface layer for both winter 2018 and spring 2019 field tests.

As shown in Figure 2, the DCP-CBR values for both the OGCS and control sections in Washington County increased from winter to spring, while the values for the 4" cement-treated section were erratic but mostly decreased. In Howard County, the OGCS, control, and 4" slag sections all experienced decreases in DCP-CBR values from winter to spring, with the strength loss generally being smallest in the OGCS section and greatest in the control section. In Hamilton County, the OGCS section exhibited higher DCPCBR values in the spring, while those of the control section did not change much. In Cherokee County, the OGCS section exhibited a significant decrease in DCP-CBR values (but still greater than the control section's), while both the control and slag sections exhibited little change.

The primary difference setting Cherokee apart from the other three counties is that Cherokee have a continuous thick layer of sandy gravel grading to sand and finally transitioning to silt at a depth of a few feet, while the other three counties have a stiff clay subgrade directly below the 4" surface aggregate layers. Also, 13\% of the optimized gradation in Cherokee 


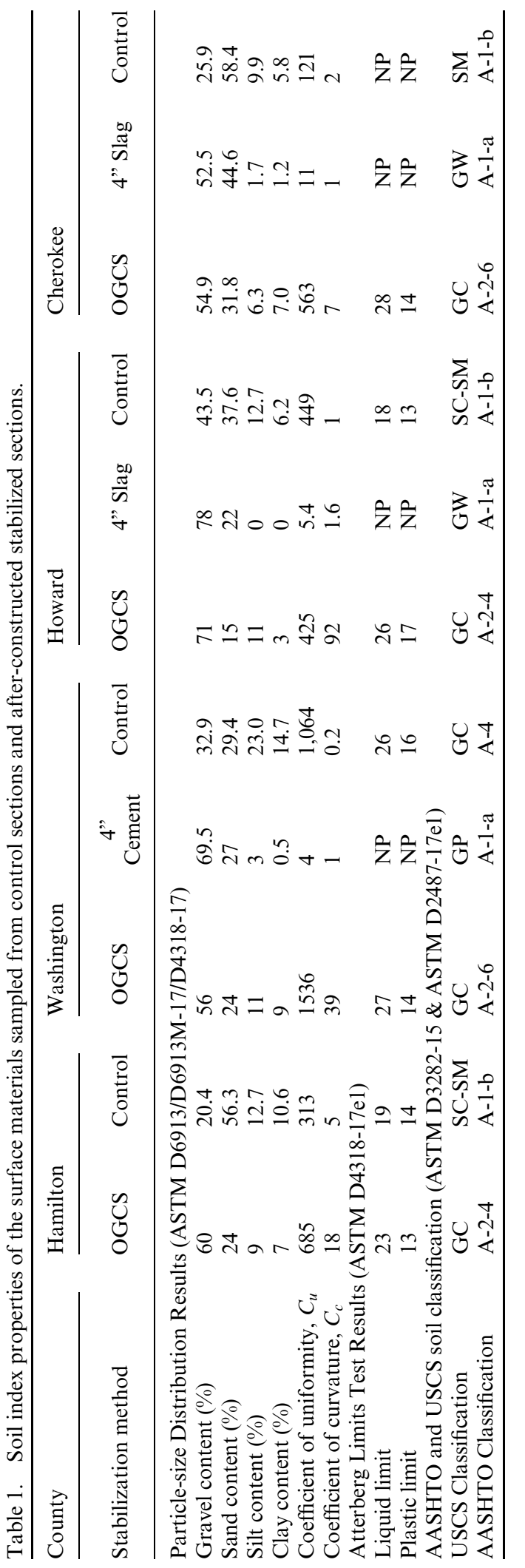




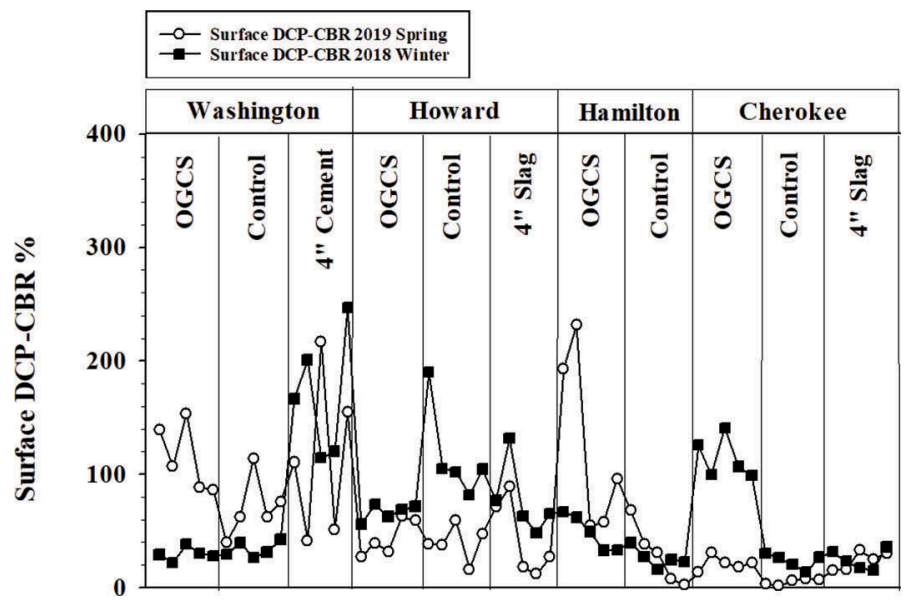

Figure 2. Results of shear strength for surface layers (five points evenly distributed in each section).

consisted of river rock, the most common surfacing material in that county, while the other counties typically used crushed limestone. Based on the data shown in Figure 2, different subgrade support conditions and inclusion of river rock can reduce the strength of the OGCS method over time, while the subgrade and surfacing materials in Washington and Hamilton counties lead to strength increases for this method.

\subsection{Falling-Weight Deflectometer (FWD) tests}

The FWD tests were conducted using a JILS model SN121 FWD with a two-piece segmented loading plate. The FWD model used nine sensors with horizontal spacings between 6 and 12 inches $(152.4$ to $304.8 \mathrm{~mm}$ ) to measure deflections on the road surface and provide a measured deflection basin. Three different target dynamic pressures of 250, 275, and 300 $\mathrm{kPa}$ were applied on the plate. The upper limit of $300 \mathrm{kPa}$ was necessary to avoid overranging the deflection sensors for the relatively compliant unpaved road surface. The combined Boussinesq-Odemark solution was utilized to obtain stresses, strains, and deformations at each given depth and radii for a homogeneous, linear-elastic half-space model [16]. In conformance with this combined theory, back-calculation was performed based on dynamic loads and peak deflections observed under the geophones in the two-layered system [17]-[22].

Figure 3 shows the surface elastic modulus (termed $\mathrm{E}_{\mathrm{FWD}}$ ) determined from FWD tests performed at five points in each section during winter 2018 and spring 2019. In Washington County, $\mathrm{E}_{\mathrm{FWD}}$ for the OGCS and control sections did not exhibit any statistically significant changes from winter to spring (one point in each section was stiffer in spring). However, in the 4" Cement section the modulus underwent a considerable decrease from winter to spring. In Howard and Cherokee Counties, the maximum change of $\mathrm{E}_{\mathrm{FWD}}$ occurred as decreases in the OGCS section in Howard County and the OGCS and 4" slag sections in Cherokee county. The maximum decrease in $\mathrm{E}_{\mathrm{FWD}}$ among all sections was in the OGCS section in Hamilton County; this section exhibited the highest average initial $\mathrm{E}_{\mathrm{FWD}}(\sim 18,000 \mathrm{MPa})$ compared to all sections during winter 2018 (due to the frozen ground in accordance with the weather information that day). The modulus for this section decreased significantly during spring 2019, becoming similar to that of the other sections $(\sim 1,300 \mathrm{MPa})$. The $\mathrm{E}_{\mathrm{FWD}}$ for the control section also decreased slightly from winter 2018 to summer 2019 in Hamilton. 


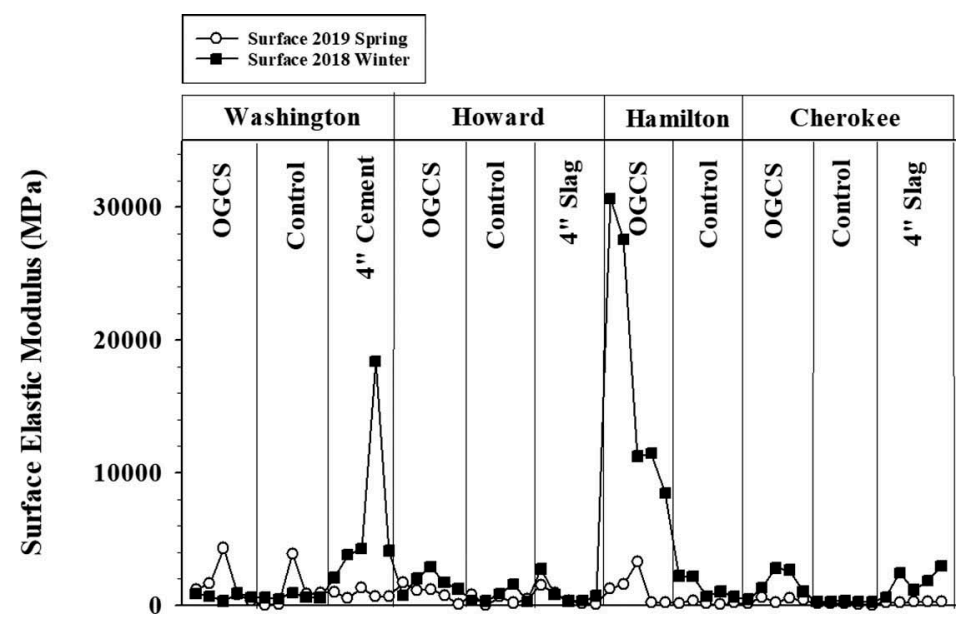

Figure 3. Elastic modulus of granular surface layers determined from FWD tests (five points evenly distributed in each section).

\subsection{Nuclear gauge \& result summary}

Nuclear-gauge tests were conducted in the four counties to monitor changes in water content $(\varpi)$ and dry density $\left(\mathrm{\gamma}_{\mathrm{d}}\right)$ of the surface aggregates. The average results for $\omega$ and $\mathrm{yd}$ are shown in Table 2, along with the average values of $\mathrm{E}_{\mathrm{FWD}}$ and DCP-CBR for all sections.

Based on the average values reported in Table 2, the cement-stabilized surface section in Washington County, the control sections in Howard and Cherokee counties, and the steel slag section in Howard County all exhibited significant decreases in CBR, indicating that these sections lost shear strength during spring thawing. The OGCS and control sections in Hamilton, Howard, and Cherokee counties, as well as all slag and cement sections, experienced significant decreases in elastic modulus during the spring thaw as well. However, the average strength and stiffness for all OGCS and cement-stabilized sections were higher than those of the corresponding control sections in all four counties after the spring thaw. The moisture

Table 2. Test result summary for Winter 2018 and Spring 2019 (average values for five tests in each section).

\begin{tabular}{|c|c|c|c|c|c|c|c|c|c|}
\hline \multirow{2}{*}{ Section } & & \multicolumn{2}{|c|}{ Avg. DCP-CBR (\%) } & \multicolumn{2}{|c|}{ Avg. $\mathrm{E}_{\mathrm{FWD}}(\mathrm{MPa})$} & \multicolumn{2}{|c|}{ Avg. $\gamma_{d}\left(\mathrm{kN} / \mathrm{m}^{3}\right)$} & \multicolumn{2}{|c|}{ Avg. $₫(\%)$} \\
\hline & & $\mathrm{F}^{1}$ & $S^{2}$ & $\mathrm{~F}$ & $\mathrm{~S}$ & F & S & $\mathrm{F}$ & S \\
\hline \multirow{4}{*}{ Washington } & OGCS & 29.7 & 114.9 & 683.9 & $1,672.3$ & 21.6 & 21.5 & 6.0 & 5.8 \\
\hline & Cement & 169.9 & 115.1 & $6,547.6$ & 846.7 & 20.3 & 20.0 & 9.2 & 8.2 \\
\hline & Control & 33.9 & 70.9 & 645.4 & $1,162.6$ & 20.2 & 20.5 & 7.9 & 6.3 \\
\hline & OGCS & 66.6 & 44.4 & $1,728.6$ & 984.4 & 19.8 & 19.3 & 7.4 & 6.3 \\
\hline \multirow[t]{2}{*}{ Howard } & Slag & 77.1 & 43.4 & 555.8 & 363.6 & 26.4 & 25.3 & 4.3 & 3.5 \\
\hline & Control & 116.7 & 39.7 & 691.9 & 426.3 & 20.8 & 18.9 & 7.8 & 6.7 \\
\hline \multirow{3}{*}{ Hamilton } & OGCS & 48.9 & 126.7 & $17,882.7$ & $1,316.5$ & 20.7 & 22.1 & 5.7 & 3.7 \\
\hline & Control & 26.0 & 109.9 & $1,356.4$ & 189.05 & 20.2 & 20.0 & 9.5 & 9.1 \\
\hline & OGCS & 114.4 & 21.2 & $1,666.2$ & 388.4 & 21.1 & 21.1 & 7.1 & 5.2 \\
\hline \multirow{2}{*}{ Cherokee } & Slag & 24.7 & 23.9 & $1,363.7$ & 257.1 & 25.04 & 26.3 & 3.6 & 2.4 \\
\hline & Control & 23.6 & 5.2 & 284.9 & 120.9 & 20.5 & 20.7 & 9.9 & 5.4 \\
\hline
\end{tabular}

1 Fall 2018, ${ }^{2}$ Spring 2019 
contents of all the control sections were found to be slightly higher than all other sections, with the exception of the cement-stabilized surface.

\subsection{Cost comparison}

For all the test sections, the construction and maintenance costs were tracked over the duration of the project. Figure 4 shows a summary of the construction costs.

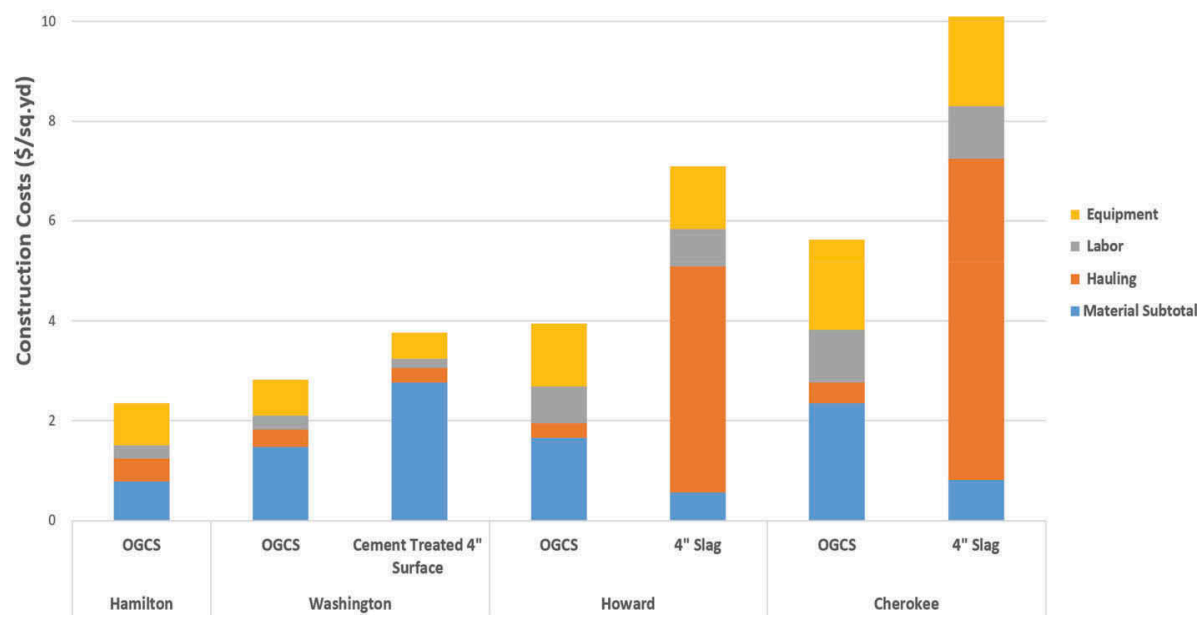

Figure 4. Construction and maintenance costs (\$/sq.yd.) for stabilized sections in all four counties.

According to Figure 4, the two steel slag sections had relatively high costs compared to the other sections. The hauling cost was the most significant component for the slag sections, but this cost could be significantly lower for counties located close to a slag source. The cost for Portland cement materials comprised approximately $80 \%$ of the construction costs for the cement-stabilized section, and it should be noted that a rental cost was not incurred for the milling machine as it was owned by Washington County. Construction costs for the OGCS sections included hauling costs which depend on distance from the supplier on the eastern border of the state, and several hours of blade-mixing and rolling. The aggregate materials used in the OGCS sections came from the local quarries in each county.

After construction was finished, maintenance records including cost summaries were recorded by county engineers. Details of maintenance costs during the first year incurred by blading and spreading fresh aggregate over the test sections as needed are given in Table 3 (information from Cherokee County was not available). Maintenance costs in each section were minor compared to construction costs. In Hamilton county, the entire cumulative length of test sections was bladed instead of treating them separately. The control section in Howard county had a maintenance cost greater than four times that of the stabilized sections.

Beyond having a reasonable construction cost, to be cost-effective a stabilization method should have relatively good strength and binding properties that can be maintained for a reasonable length of time. The corresponding construction method should be easily achievable using readily-available equipment and materials. Because hauling costs will depend on distance from the stabilizer source, their contribution to the overall construction and maintenance costs should be carefully considered by secondary-road agencies. 
Table 3. Construction costs for the four counties (2018-2019).

\begin{tabular}{lllllrl}
\hline County & Detail & Section Name & $\begin{array}{l}\text { Material } \\
\text { Cost }(\$)\end{array}$ & $\begin{array}{l}\text { Equipment } \\
\text { Cost (\$) }\end{array}$ & $\begin{array}{l}\text { Labor } \\
\text { Cost (\$) }\end{array}$ & $\begin{array}{l}\text { Cost } \\
\text { (\$/sq. } \\
\text { yd.) }\end{array}$ \\
\hline \multirow{3}{*}{ Howard } & 1.42hrs blading & OGCS & NA & 99.49 & 51.37 & 0.073 \\
& 1.9hrs blading & Control & 497.60 & 133.01 & 68.68 & 0.340 \\
Washington & 0.75hrs blading & 4" Phoenix Slag & NA & 52.48 & 27.10 & 0.077 \\
Hamilton & 3hrs blading & Entire 1 mile & NA & 228.45 & 123.69 & 0.030 \\
\hline
\end{tabular}

\section{CONCLUSIONS}

While most of the stabilized test sections lost surface and subgrade strength and exhibited a decrease in elastic modulus due to effects of freezing and thawing, according to the test results not all counties lost strength after the winter season. The main conclusions with respect to the stabilization methods examined in this paper are as follows:

- The OGCS method exhibited good average strength that actually increased after the spring thaws in Howard and Washington counties, but decreased after spring thawing in Cherokee and Hamilton counties. The method was therefore found to be more effective in counties with clayey subgrades, and experienced significant strength loss in the county with a sandy subgrade. However, in all four counties the average strength and stiffness in the OGCS sections after the spring thaw were greater than those of the nearby control sections. The construction and maintenance costs for this method were also relatively low compared to the other two stabilization methods examined. Overall, while the OGCS method appears to be a cost-effective stabilization alternative easily achievable in Iowa, further observation is required to evaluate this method's long-term performance.

- While the steel slag sections exhibited good strength in both Howard County and Cherokee County, the cost of hauling steel slag can be significant depending on distance from available sources.

- The cement-stabilized surface course treatment exhibited a large increase in average strength that decreased after the spring thaw but remained higher than that of the control section. The stiffness was greatly improved after construction but fell below that of the control section after spring. Based on these conclusions, the 4" cement-stabilized surface is also recommended as a cost-effective alternative.

According to the test results, maintenance logs, and survey photos of the test sections, not all sections suffered from a significant strength decrease after the spring thaw. Based on cost and performance comparisons, the optimized gradation with clay slurry and 4" cementstabilized surface methods appear to be the most cost-effective alternatives among those examined in this study.

\section{ACKNOWLEDGEMENTS}

This research was supported by the Iowa Department of Transportation through IHRB Project TR-721. This support is gratefully acknowledged. The findings and opinions expressed herein are those of the authors and do not necessarily reflect the views of the Iowa DOT. The authors wish to thank County Engineers Nick Rissman, Nicole Stinn, Jacob Thorius, and Brandon Billings as well as their crews for assistance in construction and maintenance of the test sections. The authors also thank the representatives of the slag source and the sand company providing the clay slurry for overseeing and providing input during construction of the related test sections. 


\section{REFERENCES}

[1] C. Li, P. K. R. Vennapusa, J. Ashlock, and D. J. White, "Mechanistic-based comparisons for freeze-thaw performance of stabilized unpaved roads," Cold Reg. Sci. Technol., vol. 141, no. June, pp. 97-108, 2017.

[2] S. Satvati, J. C. Ashlock, A. Nahvi, C. T. Jahren, B. Cetin, and H. Ceylan, "A Novel Performance-Based Economic Analysis Approach: Case Study of Iowa Low Volume Roads.," in 12th TRB International Conference on Low-Volume Roads, 2019.

[3] C. Li, J. C. Ashlock, D. J. White, and P. K. R. Vennapusa, "Mechanistic-based comparisons of stabilised base and granular surface layers of low-volume roads," Int. J. Pavement Eng., pp. 1-13, 2017.

[4] A. J. Puppala, Estimating stiffness of subgrade and unbound materials for pavement design, vol. 382. Transportation Research Board, 2008.

[5] E. Kausel and J. M. Roesset, "Stiffness matrices for layered soils," Bull. Seismol. Soc. Am., vol. 71, no. 6, pp. 1743-1761, 1981.

[6] M. Mahedi, S. Hossain, M. Faysal, M. S. Khan, and A. Ahmed, "Prediction of Strength and Stiffness Properties of Recycled Pavement Base Materials Using Non-Destructive Impact Echo Test,"sin International Congress and Exhibition"Sustainable Civil Infrastructures: Innovative Infrastructure Geotechnology," 2017, pp. 121-136.

[7] P. K. R. Vennapusa, M. Asce, D. J. White, and M. Asce, "Performance Assessment of Secondary-Roadway Infrastructure in Iowa after 2011 Missouri River Flooding,” vol. 3, no. 4, pp. $1-11,2015$.

[8] D. J. White, Low-Cost Rural Surface Alternatives : Literature Review and Recommendations. 2013.

[9] P. K. R. Vennapusa, D. J. White, J. Siekmeier, and R. A. Embacher, "In situ mechanistic characterisations of granular pavement foundation layers," Int. J. Pavement Eng., vol. 13, no. 1, pp. 52-67, 2012.

[10] T. liang Wang, Y. jun Liu, H. Yan, and L. Xu, "An experimental study on the mechanical properties of silty soils under repeated freeze-thaw cycles," Cold Reg. Sci. Technol., vol. 112, pp. 51-65, 2015.

[11] A. E. Johnson, "Freeze-thaw performance of pavement foundation materials." Iowa State University, 2012.

[12] I. Qamhia, E. Tutumluer, L. C. Chow, and D. Mishra, "A Framework to Utilize Shear Strength Properties for Evaluating Rutting Potentials of Unbound Aggregate Materials," Procedia Eng., vol. 143, no. Ictg, pp. 911-920, 2016.

[13] E. Tutumluer, I. I. A. Qamhia, and H. Ozer, "Field Performance Evaluations of Sustainable Aggregate By-product Applications," in Geotechnics for Transportation Infrastructure, Springer, 2019, pp. $3-23$.

[14] J. C. Ashlock, Y. Wu, B. Cetin, H. Ceylan, and C. Li, "Construction of Chemically and Mechanically Stabilized Test Sections to Reduce Freeze-Thaw Damage of Granular Roads," in 12th International Conference on Low-Volume Roads, 2019, p. 58.

[15] W. H. Chesner, R. J. Collins, M. H. MacKay, and J. Emery, "User guidelines for waste and byproduct materials in pavement construction," Recycled Materials Resource Center, 2002.

[16] AASHTO, "AASHTO Design Guide for Pavement Structures," Am. Assoc. State Highw. Transp. Off. Washington, D.C, 1993.

[17] M. R. Stokoe, K.H. II, Wright, G.W., James, A.B., and Jose, M. R. "Characterization of geotechnical sites by SASW method," pp. 15-25, 1994.

[18] M. Saltan, V. E. Uz, and B. Aktas, "Artificial neural networks-based backcalculation of the structural properties of a typical flexible pavement," Neural Comput. Appl., vol. 23, no. 6, pp. 1703-1710, 2013.

[19] J. Boussinesq, Application dès potentiels a l'étude de l'équilibre et du mouvement des solides élastiques. Gauthier-Villars, 1885.

[20] J. Grasmick, M. Voth, and C. Senseney "Capturing a Layer Response during the Curing of Stabilized Earthwork Using a Multiple Sensor Lightweight Deflectometer," J. Mater. Civ. Eng., vol. 27, no. 6, pp. 1-12, 2014.

[21] N. Odemark, "Investigations as to the elastic properties of soils and design of pavements according to the theory of elasticity," 1949.

[22] C. Li, J. C. Ashlock, D. J. White, and P. K. R. Vennapusa, "Mechanistic-based comparisons of stabilised base and granular surface layers of low-volume roads," Int. J. Pavement Eng., vol. 8436, no. May, pp. 1-13, 2017. 
[23] C. Li, J. C. Ashlock, B. Cetin, and Jahren, C. (2018) "Feasibility of Granular Road and Shoulder Recycling", Final Report, IHRB Project TR-685, 182 pp., April 2018.

[24] Henry, S. K., Olson, P. J., Farrington, P. S., \& J, Lens,. (2005). Improved performance of unpaved roads during spring thaw (No. ERDC/CRREL-TR-05-1). Engineer Research and Development Center, Hanover NH, Cold Regions Research and Engineering Lab.

[25] C. Li, and J. C. Ashlock (2018) Gradation Optimization for Granular Surface Materials, MS Excel Spreadsheet, https://intrans.iastate.edu/research/completed/feasibility-of-gravel-road-and-shoulderrecycling/.

[26] ASTM D2487 - 17 (2017). Standard Practice for Classification of Soils for Engineering Purposes (Unified Soil Classification System), ASTM International, West Conshohocken, PA.

[27] ASTM D3282-15 (2015). Standard Practice for Classification of Soils and Soil-Aggregate Mixtures for Highway Construction Purposes, ASTM International, West Conshohocken, PA.

[28] ASTM D4318-17e1 (2017). Standard Test Methods for Liquid, Plastic Limits, and Plasticity Index of Soils, ASTM International, West Conshohocken, PA.

[29] ASTM D6913/D6913M-17 (2017). Standard Test Methods for Particle-Size Distribution (Gradation) of Soils Using Sieve Analysis, ASTM International, West Conshohocken, PA.

[30] ASTM D7928-17 (2017). Standard Test Method for Particle-Size Distribution (Gradation) of FineGrained Soils Using the Sedimentation (Hydrometer) Analysis, ASTM International, West Conshohocken, PA. 